\title{
Counselor Perceptions: Let Us Do Our Job!
}

\author{
Stephen Benigno ${ }^{1}$ \\ ${ }^{1}$ Texas A\&M International University, Laredo, TX, USA \\ Correspondence: Stephen Benigno, Texas A\&M International University, Laredo, TX, USA. E-mail: \\ sbenigno@tamiu.edu
}

Received: June 2, 2017

Accepted: June 23, $2017 \quad$ Online Published: July 5, 2017

doi:10.5539/jel.v6n4p175

URL: http://doi.org/10.5539/jel.v6n4p175

\begin{abstract}
Elementary and Middle school administrators continually struggle with developing instructional programs that will address the academic and human developmental levels of the students in their care. Addressing the human development and the academic issues related to the elementary and middle school student is only a small percentage of the attention required for that student. Many students at the elementary and middle school levels encounter issues related to social and emotional development that are often overwhelming and many times detrimental to the academic development of those students. School administrators address those issues by utilizing the existing infrastructure of the schools. One of the key components of the school infrastructure is the school counselor. In some situations, school counselors are being required to perform duties outside the realm of their perceived responsibilities. This study was conducted to ascertain school counselor perceptions with respect to job performance, expectations, satisfaction and responsibility. The results of the study indicated that the counselors involved in the study believed that they are being required to perform duties outside the realm of their responsibilities and that the performance of these duties has an impact on their effectiveness as school counselors.
\end{abstract}

Keywords: effectiveness, collaboration, systems, stakeholders, perceptions

\section{Introduction}

Elementary and middle school counselors are expected to provide guidance counseling in a systematic way to all students and they are expected to address the immediate concerns of students and assist students in monitoring and understanding their own development. School counselors have extensive training in specific skill sets that enable them to address many of the social and emotional issues that face the elementary and middle school student. In light of this training, many counselors have specific perceptions as to what they should be doing in their positions as elementary and middle school counselors.

One of the core characteristics of a successful school is the emphasis and utilization of the school counselors within the instructional program. Effective schools are successful in mobilizing both the academic core of schools-teaching and learning-as well as practices such as guidance counseling, teacher teams and extracurricular activities, which encourage affective relationships between adults and students (Ingersoll, 2003). According to the National Forum to Accelerate Middle-Grades Reform, there are three priorities or interlocking themes that are characteristic of successful schools; academic excellence, developmental responsiveness and socially equitable and fair policies. The counseling program within the school can be instrumental in facilitating the development of these themes and priorities. Academic excellence can be reinforced and supported by receptive and available counseling services to all students. An ongoing systematic process of monitoring, mentoring, reporting and intervention will insure that teachers and administrators are attentive to the specific needs and trends in the building with respect to the academic wellbeing of the students.

Addressing the individual needs of the elementary and middle school students requires individualized attention. The developmental levels of the students can be extreme during these formative years. The developmental changes in students during this age period can be radical and require that counselors meet with individual students frequently to assess, evaluate and plan for the possible interventions that may be required. In addition to addressing the academic and developmental needs of the student, counselors are often required to address the social forces that impact the elementary and middle school community. Family, 
peer and community stressors can impact the delicate psyche of the elementary and middle school student. Counselors are required to have the pulse of the school community through an ongoing conversation with students, parents, teachers and administrators. This articulation between and among the stakeholders of the school community will enable the counseling department to prioritize, emphasize and implement programs that will address the particular needs of individual students, groups of students or institutions within the school that need assistance. Equitable, transparent opportunities can be provided to all students through this ongoing collaboration.

Effective schools have specific characteristics that make the operation of the entities receptive and conducive to the transformational development of a productive school culture. One of the essential characteristics is the identification and development of the individual roles within the organization. This theory, as defined by Von Bertalaffy (1956) is a system of complex interacting elements known as the Systems Theory. Senge (1990) also looks at the systems process as a basis for the development of three core learning capabilities, the fostering of aspiration, the development of reflective conversation and the understanding of complexity to address value generation. An organization that develops and encourages empowerment through this Systems Theory does so by allowing individuals within the organization an opportunity to grow productively within the parameters of their specific roles. People feel empowered and they develop an affinity for performing their responsibilities at a high level of effectiveness. They engage in collegial conversation and reflect on their performance because they recognize their role in the organization and they want to be a high level contributor to the goals and vision of the organization.

Effective principals and administrators utilize the Systems Theory to maximize the utilization of the individuals within their organization. Transformational leaders empower stakeholders within the system to recognize their responsibilities and be "all that they can be" within the parameters of their roles. Stephen Covey conveys in his book "The Seven Habits of Highly Effective People" that individuals within the system should recognize their "circle of influence" and that they should work within that circle to maximize the efficiency of their roles. Unfortunately some administrators in schools force individuals out of their zone of expertise and require those individuals to perform duties that are out of the realm of their responsibility.

Elementary and middle school counselors are confronted on a daily basis with issues that challenge this System Theory. Counselors are often required to perform duties outside the realm of their perceived responsibilities. Counselors at the elementary and middle school level are often assigned duties that take them away from their counseling responsibilities. These additional assignments may cause the counselors to put existing responsibilities on hold, cancel appointments with parents, meetings with students and teachers, and cause delays in the dissemination of requirement documentation. This deviation from their assigned duties can stimulate feelings of distress and frustration in the counselors with respect to the expectations of their perceived roles and responsibilities. The disruption in the day to day operation of the school may also be impacted by these additional assignments as counselors may not be available to execute their traditional duties.

Administrators and particularly principals are also faced with complex issues when addressing the utilization of the instructional, classified and counseling personnel. Throughout the course of the school year and sometimes during the planning phases of the year, school administrations are often required to develop and implement policies that necessitate the use these individuals in positions that are not necessarily within their specific areas of expertise. Teachers are often utilized in supervisory roles and asked to, monitor the halls during passing periods, supervise the lunch, host breakfast in their classrooms, monitor arrival and departure procedures and collaborate during their individual planning periods. Classified individuals, instructional aides, custodians, parent facilitators and cafeteria personnel may also be required to do much of the same. Counselors are also utilized by the school administrations to provide additional resources and manpower. Their expertise in the areas of organization, communication and curriculum are invaluable assets to the school community. Administrators often find it necessary to tap into those valuable resources. Counselors often know many of the students, have experience working with groups of students and teachers, are knowledgeable about curriculum and instruction and often have the pulse of the school culture. Additionally administrators often perceive that counselors sometimes have more flexibility with respect to their work schedules and their assignments.

\section{Method and Participants}

This study was conducted to ascertain the extent to which counselors working at the elementary and middle school levels perceived that they were being required to perform duties outside the realm of their responsibilities. Counselors in a South Texas school district were anonymously surveyed to gather data that would indicate counselor perceptions with respect to their job satisfaction, assigned duties and responsibilities. Fifty elementary 
and middle school counselors were chosen to participate in the study. Counselors were apprised of the study in advance during a district meeting of elementary and middle school counselors. The survey was constructed using specific questions related to job satisfaction, management performance and communication, decision making, culture and job responsibilities. The survey was disseminated to the counselor subjects through email. The questions were pre-populated using a Likert Scale which measured responses from a range of strongly disagree to strongly agree. One narrative response question was asked at the end of the survey in an attempt to solicit suggestions for improvement in working conditions and effectiveness of job performance. Fifty respondents were solicited and fifty responses were received.

\section{Results}

The first question of the survey asked the respondents if they were satisfied with their opportunities for professional growth. Fifty-four percent or twenty-seven respondents indicated that they were satisfied with their professional development while thirty-four percent or seventeen respondents indicated a dissatisfaction with the opportunities. The narrative responses to this question posited suggestions for improvement in the area of professional growth,

"I would like to see more professional development opportunities geared towards counseling and not just towards administrative duties". "Annual refresher training on new procedures and/or modified procedure from previous programs and/or plans". "More emphasis/guidance on how to counsel students with specific emotional problems, training on how to write counseling goals and objectives for counseling IEPs". "We need better training from our counseling director". "Moneys need to be allocated to the counseling department in order to get all elementary counselors materials on the topics covered each month".

The second question of the survey asked the respondents if they were inspired to meet their goals. Eighty-five percent or thirty nine respondents indicated that they were inspired to meet their goals while eleven percent disagreed with the question and indicated that they were not inspired to meet their goals. None of the narratives addressed the question of inspiration.

The third question of the survey asked the respondents if they had a good working relationship with their supervisor. Ninety-five percent or forty-four respondents agreed that they did have a good working relationship with their supervisor. One responded expanded on the question and explained,

"I am currently at a campus where the principal is excellent. Our principal knows how to set the example of being a leader. I come from a previous school where that was not the case. I come from a school where counselors did so MANY things that were not in a counselor's duties. There were two of us as counselors in that previous school and we still had an overload of duties, most especially duties that were not counselor-related. In my current school, we are given duties that are counselor-related and that makes it much more rewarding to come to school. We are able to have counseling classes twice a month and still be able to see students on an individual basis. It would be great if all principals followed our school's principal's work ethic and leadership skills in order to have all counselors within our district feel content being a counselor".

The fourth question of the survey asked the respondents if they were able to make decisions affecting their work. Eighty percent or thirty-seven respondents indicated that they were able to make decisions affecting their work. Twelve percent or six respondents felt that they were not able to make decisions affecting their work. One respondent expanded on the question by positing,

"I believe that as long as a counselor is highly involved with her students and maintains a good working relationship with her colleagues, her responsibilities and yearning to do more within the school will never be questioned".

The fifth question of the survey asked the respondents if the communication between senior leaders and employees was good in the organization. Sixty-four percent or twenty-nine agreed that the communication was good and eighteen percent or eight disagreed that communication was good. Some of the comments from the narratives suggested that,

"Communication between supervisor and employees needs to improve. Job expectations need to be communicated clearly to all employees. Work duties need to be distributed equally among employees. Administrative duties must be removed from counselors so that counselors are available to counsel students". 
"The school where I work, and my administrations are great. On the other hand I would like to see more professional development opportunities geared towards counseling and not just towards administrative duties".

The sixth question of the survey asked the respondents if they got excited about going to work. Eighty one percent or thirty-eight respondents indicated that they did get excited about going to work. Nine percent or four individuals disagreed and indicated that they did not get excited about going to work. None of the narrative responses addressed a comment related to their level of enthusiasm for going to work.

The seventh question of the survey asked respondents if they perceived that management within the organization recognized strong job performance. Fifty-eight percent or twenty-seven respondents believed that management did recognize strong job performance while seventeen percent or eight respondents disagreed. Twenty-three respondents or eleven individuals were neutral on the question. Two comments related to the recognition question suggested,

"Too many chiefs and not enough Indians... We need help; we just don't know where to look for it without our names going on the 'black list' of troublesome people".

"The role of a school counselor is not understood at all or viewed as not as important, therefore it seems like we do not have much to do. Additional duties (unrelated to our role) are given to us because we are seen as extra staff and therefore given miscellaneous tasks. These additional duties take up a great amount of time that our primary (school counselor's) duties are not a priority at all".

Question eight posited, "I am satisfied with the culture of my workplace". Seventy-one percent agreed with that question, fifteen percent disagreed and thirteen percent or six respondents were neutral. None of the individual narrative responses addressed culture.

Question nine asked if the respondents were completely involved in their work. Eighty-one percent or thirty-seven agreed with the statement, thirteen percent were neutral while three respondents disagreed with the statement.

The tenth question asked the respondents to rate the decisions that were being made by their supervisors. Fifty-five percent or twenty-six respondents indicated that decisions were reasonable, thirty-four percent or sixteen felt that they were somewhat reasonable, while eight percent or four individuals felt that the decisions were no at all reasonable. A comment from one respondent suggested that administrators,

"Value the counselor's time (Some clerical duties that do not pertain to counseling should be delegated to others, i.e., collecting for United Way, ordering awards, decorating bulletin boards, etc.). Provide the time that will allow counselors to establish good rapport with the students whom they service. Across the board, the counseling department should delineate the time that is spent on counseling verses extra duties".

The eleventh question asked the respondents if they clearly understood what was expected of them in their position. Eighty-six percent or forty respondents agreed that they clearly understood what was expected of them on the job but one respondent suggested that,

"Job duties need to be clearly established and communicated to campus principals and administrators".

"Re-evaluation of additional duties given to counselors is needed. Often times, there are major duties assigned that consume our day that could be handled differently. All schools should also be the same. It often feels that the role of a counselor is not what it should be".

\section{Discussion}

The survey was structured to gather respondent perceptions on specific areas of inquiry. Of specific interest to the researcher were questions one, twelve and thirteen. The area of professional development was addressed in question one. Even though only thirty-four percent or seventeen respondents indicated a dissatisfaction with the opportunities for professional development, the researcher felt that the one third who were unhappy with the professional development warranted discussion. With the constantly changing educational environment that counselors are required to maneuver during their careers, professional development related to those environmental challenges should be provided to the professionals in the field. Refresher training, guidance on counseling strategies, direction for the development of goal setting and specific training aimed at working with the students with emotional disabilities were suggested by the respondents. All of the recommendations addressed issues of relevance within the educational environment and the implementation of those suggestions are warranted. 
Question twelve was constructed to ascertain the level of respondent concern with respect to the counselor's required assigned duties. Ninety percent of the respondents agreed or strongly agreed with the question, "that they were performing duties outside of their perceived responsibilities". Most of the narratives submitted addressed this question. Many of the respondents wrote very passionate statements and reflections that demonstrated serious concern and frustration with the issue. It is obvious that school administrators need to address this issue with the counselors and have a very transparent and psychologically safe conversation with the counselors concerning this issue. The responses in the narrative field of question twelve addressed specific concerns related to the required duties of the respondents. Lunch duty, hall duty and the planning of school wide activities were revealed as activities that contributed to the inability of the respondents to meet with students. Some suggestions from the narrative section:

"Some of the extra duties like lunch duty or hallway monitoring take away valuable time each day that could be spent on direct interaction with students". "A lot of time is also spent on planning school wide programs/organizing events, G.T testing, and other paperwork such as Special Education referrals, RTI, different reports. It would be great if we would only be responsible for guidance classes and counseling".

"Counselors, as well as teachers in the district, are swamped with documentation and all kinds of deadlines and testing. Way too many 'duties' are thrown at us (counselors) with the excuse of this new trend of 'multitasking'. If we are to do our job right, we need time. The way things are right now, everything is a 'drive-by', 'check it off your list' kind of thing".

"The assistance of a clerk/paraprofessional to help with clerical duties. School counselors wear MANY hats and the paperwork is NEVER ending. Librarians, Nurses, Coaches and others on campus have assistants, yet elementary school Counselors do not have an assistant. I have to meet district deadlines along with too many projects, conferences, meetings, counseling classes and daily impromptu activities take much of our time as professionals".

"As a counselor, I feel that we disconnect from the relationships we've established with our students because coordinating for upcoming state assessments or the GT program forces us to cancel guidance".

The thirteenth question asked the respondents if they ever felt overwhelmed by the responsibilities of their position. Fifty-four percent or twenty-five respondents strongly agreed, thirty percent or fourteen neither agreed nor disagreed and fourteen percent or seven disagreed. The fact that over half of the respondents indicated that they were overwhelmed by the responsibilities of their position would seem to raise a red flag. Counselors are trained to operate with emotional intelligence and this response would seem to warrant attention. Some comments related to question thirteen:

"Job duties need to be clearly established and communicated to campus principals and administrators".

"I am extremely disappointed and overwhelmed at this point in my career. I used to look forward to going to work; now I dread it. My job is a huge stressor in my life. My job is to help people feel better. I am supposed to have a positive and optimistic influence on students and their families. It's hard to be that person when you feel the way I do now. I feel like I'm failing at my job. I am not proud about the quality of my work".

\section{Further Study}

The survey responses stimulated several questions for further study. The counselors in the study, for the most part, did believe that they were being required to perform duties outside the realm of their perceived responsibilities. Hall duty, gifted and talented testing, IEP meetings and RTI scheduling were among the duties that were identified as being problematic. The difference between the perceived responsibilities and the assigned responsibilities of the counselors needs further clarification. What are the specific responsibilities of counselors at the elementary and middle school level? Are the assigned duties actually within the realm of the counselor's responsibilities? Are administrators who assign duties aware of counselor responsibilities and do the administrators take into consideration counselor responsibilities when they assign duties? Further investigation and research is needed in these areas. Further inquiry into the responses to question thirteen could also be beneficial. Twenty-five respondents did indicate that they were overwhelmed by the responsibilities of their position. Were the respondents overwhelmed because of the additional duties or were other factors instrumental in causing the respondents to be overwhelmed? Further investigation and research is needed in this area. 


\section{Conclusion}

Open communication that provides multiple opportunities for input to decision making, mutual trust and mutual respect are key characteristics of an effective relationship between the administration and counselors. The identification and the designation of the counselor's role within the educational environment should be collaboratively discussed between the administration and the school counselors. Creating a collegial conversation and a cooperative understanding between the administration and the counselor will help to define the role responsibility of the counselor and help those individuals intertwine their responsibilities with the goals of the school administration. That communication and inclusive conversation could also enhance the counselor's understanding and perspective as it applies to the operation of the school. This empowerment through a collegial and communicative strategy could stimulate a collaborative and collective ownership in the process. This ownership in the process may create a transformative relationship between the counselors and the administration and that relationship may facilitate an implementation strategy that could evolve the school into a high performing organization.

Specific strategies for developing a collaborative relationship between the administration and the counseling department should include multiple inclusive opportunities for the administration and the counseling department to plan and organize together. These opportunities could occur during the planning stages of the year and the operational periods of the year. The administration could develop these opportunities for the counselors by adding them to the leadership team and by including the counselors in the development of the school vision and mission statements. Counselors could also be given opportunities to collaborate with teachers and grade level leaders. These opportunities will permit the counseling department to become acquainted with the instructional staff and that relationship could possibly benefit all parties.

Critical in the strategy to developing an inclusive relationship is the development of trust between the administration and the counseling department. According to Stephen Covey, "trust is the glue of life. It's the most essential ingredient in effective communication. It's the foundational principle that holds all relationships". Gaining that trust through empowerment, collegial conversation, shared decision making and collaboration could establish the foundation for a highly effective learning community.

\section{References}

Covey, S. (1989). The seven habits of highly effective people. Free Press.

Ingersoll, R. M. (2003). The wrong solution to the teacher shortage. Keeping Good Teachers, 60(8), 30-33.

Senge, P. M. (1990). The fifth discipline: The art and practice of the learning organization. Doubleday, Random House Inc.

The National Forum to Accelerate Middle-Grades Reform. (2010). Social equity and closing the achievement gap. Policy Statement, 2.

Von Bertalanffy, L. (1972). The history and status of general systems theory. Trends in General Systems Theory, New York, Wiley-Interscience.

\section{Copyrights}

Copyright for this article is retained by the author(s), with first publication rights granted to the journal.

This is an open-access article distributed under the terms and conditions of the Creative Commons Attribution license (http://creativecommons.org/licenses/by/4.0/). 